\title{
Understanding the Phenomenon of Bullwhip Effect in Relation to Supply Chain Strategies: FMCG industry
}

\author{
Thokozani Patmond Mbhele \\ Lecturer School of Management of the University of KwaZulu-Natal \\ Maxwell Agabu Phiri \\ Lecturer Supply Chain Management, PhD candidate in the School of management, \\ IT \& Governance at the University of KwaZulu-Natal \\ Email address: phirim@ukzn.ac.za
}

Doi:10.5901/mjss.2014.v5n20p570

\begin{abstract}
The business environment challenges the competence of supply chain performance on responsiveness, connectivity and agility to ameliorate phenomenon of bullwhip effect. The extent of relationship between bullwhip effect and supply chain strategies should optimize product flows and availability from the amplified demand order oscillations. The study has used multiple regression techniques on 448 responses to tentatively develop the supply chain models. This study reveals that the challenges of bullwhip effect are explained by accuracy of demand forecasting, transport systems, information sharing and velocity, risk pooling system and integrated e-SCM systems. The results provide new perspective in managing amplification in the consumer demand order variability moving upstream supply chain network. The model will help to address the challenges of bullwhip effect and further enhance the overall efficient frontiers of supply chain performance. This paper provides insights to FMCG industry on using innovative strategies and modern technology to enhance supply chain visibility through integrated systems networks.
\end{abstract}

Keywords: Bullwhip effect, Information sharing, risk pooling, integrated e-SCM systems, advance economic information and FMCG industry.

\section{Introduction}

In the fast moving consumer retail downstream site of supply chain networks, the underlying appeal depends on product availability on a broad selection of goods underpinned by frequencies of order replenishment rate which are, normally not susceptible to demand order variability to efficiently maximise customer service. Hugo et al., (2008:275) support information distortion immunity that the comprehensive pattern of frequent replenishment fill rates enable an integrated supply chain to reliably deliver and sustain the cost-effective availability of a wide product range in different stores across broad geographic locations. While the upstream site in FMCG industry expects an acceptable degree of intelligent supply chain cooperation and coordination that enhance visibility of point-of-sales data. Eventually, this should contribute to updated demand and supply forecasts for better capacity planning and schedules as well as earning economies of scale. These downstream and upstream sites of supply chain networks operate on the reality of the lower margins through a high volume throughput and higher overall volume of sales with cumulative profit on generally large quantities of sales. Essentially, the lapse in integrity spurs amplification of demand order rate to exceed the actual demand order rates as the manufacturer creates an ordering policy for each item. Under these circumstances, the supply chain trading partners are expected to leverage upstream and downstream relationships to create fundamental supply chain performance outcomes while integrating the resources and capabilities of supply chain members.

The amplitude in demand order variability (DoV) as orders surge upstream the supply chain network epitomises a harmful effect known as the bullwhip effect. The real consumer demand orders are comparatively evinced less variability while trading supply chain members on the midstream and upstream stages experience the amplified order vacillations. The oscillator effect reveals a number of pernicious problem throughout the supply chain networks, as downstream sites include harmful bloated inventory and shortages with poor customer service (Makui, 2007; Croson, Donohue, Katok and Sterman, 2005; Lee and Whang, 2004). The midstream and upstream sites depict the disharmonic capacity with costs and improper planning and inconsistent scheduling in production (Balan, Vrat and Kumar, 2009; Heizer and Render, 
2008; Jacobs and Chase, 2008); Davis and Heineke, 2005). These empirical revelations exhort the supply chain trading partners to exert efforts to maximise profits through optimization of the product flows and availability as the operational imperative underpinned by electronically-enabled supply chain management systems. Electronically-enabled supply chain management has tentatively integrative prospects to manage the overall flow of products on frequencies of order replenishment rates, quasi-real-time information sharing and finance on transactional committed orders from the supplier's supplier to the customer's customer on reduced oscillator effect (Folinaset al., 2004; Chaeet al., 2005; Miao and Chen, 2005). In dealing with the Forrester effect (1958; 1961), the integration of clock speed-based flow in a given chain network involves activities such as "the sharing of information about production, inventory level, delivery, shipment, capacity, sales and performance with firms and between supply chain members" (Patnayakuni and Rai, 2002; Li and Lin, 2006).

The synthesis of the above revelations informs the thematic configuration of the study carried out for this article from the custodian of information to the lead suppliers in the industry. The purpose of this research based article is to discuss the findings of the study carried out in the selected fast moving consumer goods (FMCG) industry on the amplified consumer demand order variability (DoV) as orders cascade from downstream (retailers) to the midstream and upstream (distribution centers, manufacturers as capacitated suppliers, and lead suppliers and $n$-tiers) sites of the supply chain network. The authors synopsis consumption cycle of the end product as stable while the orders for raw material are highly variable, increasing costs and making it difficult for supply to match demand (Chopra and Meindl, 2007; Cachon and Terwiesch, 2009). The magnitude of consumer DoV is presented in the figure below where the amplification of demand orders moves all echelon parties in the supply chain away from the efficient frontier with diminishing customer service levels.

\section{Problem Statement and Research objectives}

Generally, the bullwhip effect depicts the dynamics of accumulating order rate by the downstream site that exceeds the tentatively stable actual demand rate as one communicates demand orders to the upstream supply chain site. The pernicious effect ascribes to the dearth of a holistic view of the supply chain as a cause for cascading demand order variability (DoV) upstream. The supply chain partners normally experience the cascading order variability at each supply chain echelon stage, with higher oscillations from node-to-node roaming upstream the supply chain network. The study aims to assist businesses to properly manage the pernicious effect of demand order variability and to comprehend the significance of sharing advance economic information while applying electronically-enabled supply chain management (e$\mathrm{SCM}$ ) tools to synchronise supply chain business processes. The purpose of the study aims:

- To analyse the challenges of bullwhip effect from the perspective of electronically-enabled supply chain management (e-SCM) systems, information sharing, inventory positioning and global optimisation strategies on selected fast moving consumer goods (FMCG) industry.

- To understand the relationship of the extent to which the phenomenon of bullwhip effect can be explained by electronically-enabled supply chain management systems diffusion, optimal inventory positioning, strategically-advanced economic information sharing and global optimisation strategies.

\section{Literature Review}

\subsection{Bullwhip effect and FMCG}

The integration of information technology allows for the efficient transmission of information throughout the supply chain which in-turn facilitates supply chain integration for amelioration of bullwhip effect. These analyses of FMCG retail outlets and suppliers is deliberated in terms of common strategic diffusion of the central supply chain distribution (CscD) system, supply chain structure, supply chain information technology, inventory management, expansion to African countries, improved efficiency and effect of order variability. According to Sorescuet al., (2011:7) retail business model (RBM) innovation is defined as "a change beyond current practice in one or more elements of a retailing business model (retailing format, activities and governance) and their interdependencies, thereby modifying the retailer's organising logic for value creation and appropriation". If the business model represents the firm's distinctive logic for value creation and appropriation (Teece, 2010; Zott and Amit 2010), the strategy epitomises a central, integrated, externally oriented concept of how the business will achieve these essential strategic objectives (Hambrick and Fredrickson, 2005; Gambardella and McGahan, 2010). 
In the retail perspective, the retailers must constantly look beyond the organisational boundaries to evaluate and integrate the resources and capabilities of their suppliers and customers. To a certain extent, this approach will create superior value and a competitive advantage that companies might sustain over time. Competitive advantage implies the creation of a system that has a unique advantage over competitors to create customer value in an efficient and sustainable way. Heizer and Render (2011:68) advocate "competitive advantage in terms of competing on response strategy where a set of values relate to rapid, flexible, and reliable performance". The report analysis (Warburton, 2004; Hodgson et al., 2004) describes how the retailer's order rate quickly grows to exceed the constant consumer demand rate as the amplification in orders is attributable to the retailer's ordering policy. As the manufacturer consolidates their order policy, the service levels should be dependent on frequencies of replenishment rate. The manufacturer's situation is complicated by both shipments to multiple retailers and orders to many suppliers. Warburton (2004); Lee et al., (2000) and Towill (1996) advocate that the sharing of retail sales information is a major strategy for countering the bullwhip effect, and the manufacturer's ordering policy to reduce inventory overshoot can be created through communicating the size of the consumer demand to the supplier. The companies from diverse markets have observed a phenomenon, in which order vacillations increase as orders move upstream.

Ouyang (2007:1107) refers to the bullwhip effect as "a phenomenon in supply chain operations where the fluctuations in the order sequence are usually greater upstream than downstream of a chain". The phenomenon influences profitability throughout the network with costly inventory levels and positioning (Chopra and Meindl, 2007:525). A firm's ability to establish and maintain satisfactory customer relationships requires an understanding of buying behaviour, that is the decision processes and acts of people involved in buying and using products. Miragliotta(2006:366) defines bullwhip effect as "a supply chain phenomenon revealed by a distortion (variability amplification and /or rogue seasonality) of the demand signal as it is transmitted upstream from retailers to suppliers". The demand vacillations prevail in the multiple echelon-stages as orders roaming to the upstream site of the network. Wu and Katok (2006:839850) define the bullwhip effect as "the observation that the variability of orders in supply chains increases as one moves closer to the source of production". These definitions indicate value creating systems and movement of orders linked to multiple nodes as the description of network chain structure and linkage. This study interprets the chain networks as a complex web of interconnected nodes (representing the entities or facilities such as suppliers, distributors, factories and warehouses), and links (representing the means by which the nodes are connected on supply chain mapping flows).

\subsection{Supply Chain Management}

The supply chain management focuses on the flow of physical products from suppliers through manufacturing and distribution all the way to retail outlets and customers (Simchi-Levi, et al., 2008:1). While the demand management recognises forecast development and works with the supply side to adjust the inflows of materials and products (Cachon and Terwiesch, 2009). Although demand management analyses the consumption of the sales forecast by the actual sales order rate on a continuous basis, the flow of consumer demand order information comes from many sources in supply chains. The oscillation effect on distorted order information traveling up stream indicates amplified consumer demand order variability and results in diluted accountability, fosters distrust of information and a bloated inventory level. The analysis indicates that decentralised demand information can significantly increase the variability while the centralised demand information can significantly reduce, but will not eliminate, the bullwhip effect (Simchi-Levi et al., 2008; Snyder and Shen, 2011).

Seemingly, the integration of development chain, demand chain and supply chain through information sharing mechanisms and electronically-enabled supply chain management on multi-level echelons has the propensity to enhance customer-centric business strategies and ameliorate the pernicious problem of bullwhip effect. Schroeder (2008) states that supply chain management involves a sequence of value-added processes that try to match supply and demand, while demand chain focuses on creating and managing the quantities of one or more products that can be served by a supply chain. The establishment of correlated interrelationships among these several-dimensional chains gives a chance to mitigate an accelerator effect of demand changes in the supply chain. According to Coyle et al., (2013:16) supply chain management is viewed as "a pipeline or conduit for the efficient and effective flow of products/materials, services, information and financials from the supplier's suppliers through the various intermediate organisations out to the customer's customers or the system of connected networks between original vendors and the ultimate final consumer". This study interprets supply chain management as: 1) broad and comprehensive synchronisation of flows, integratedbased activities and extended enterprise; 2) the extended enterprise crosses the boundaries of several individual organisations on underlying demand chain, demand flow, information flow, design chain, value chain, value network and service chain; 3) the supply chain performance benefits span the related and connected process activities into schematic 
network of interrelationship and interconnectivity between its elements in order to minimise system wide costs while satisfying service level requirements.

\subsection{Information Sharing}

Information sharing is the optimisation strategy to enhance active coordination and integration in the chain network, and it extenuates challenges from consumer order demand variability. Chen (2003:341) has presented a comparative analysis where a focus has been on the demand-side information, which optimises portion of the overall flow chain network. While the supply-side information evinces limited retail sales information and wavering inventory at point of sales. In the value quantification of lead time information, the inventory system is sometimes embroiled with no information (Chen and Yu, 2005), the retailer has to rely on the history of order arrivals to deduce the lead time and an attempt to align replenishment decisions must be made. "The manufacturers can rollover new and advanced products over an extended planning period using the solo-oriented strategy. When the periodic-review inventory system is coordinated, information sharing enhances the performance of both supply chain streams of trading partners" (Li and Gao, 2008:522). However, the authors further notify that "it is not possible to achieve embellished supply chain performance targets and benefits without proper coordination and better collaboration".

According to Chiang and Feng (2007:1429) "information sharing is more beneficial for the manufacturer than for the retailers in the presence of supply uncertainty and demand volatility, and value of information sharing for the manufacturer can increase or decrease with production yield variability with different cost structures and demand patterns". Li and Lin (2006:1641) further note that "information sharing and information quality may be influenced by contextual factors, such as the type of industry, firm size, a firm's position in the supply chain, supply chain length, and type of supply chain". Information velocity is a term used to describe how fast information flows from one process to another, and information volatility as the uncertainty associated with information content, format, or timing, must be handled to add value to the supply chain (Wisner and Stanley, 2008; Simchi-Levi et al., 2008). Wisner and Stanley (2008:316) further consider enabling information technologies as a replacement for human coordination, to reduce uncertainty, to promote new coordination structures and to substitute information and knowledge for inventory.

\subsection{Electronic Supply Chain Management}

These putative processes aim to simplify information flow, inventory positioning and order replenishment optimisation across supply chains. The electronically-coordinated business activities (Sebastian and Lambert, 2003) are likely to extenuate the variance amplification through electronically-enabled supply chain management (e-SCM) systems diffusion. Lin and Huang (2012:164) define e-SCM systems diffusion as "a process form internal diffusion among functional units within an organisation to external diffusion across inter-organisational trading partners when e-SCM becomes an integral part of the value activities". Electronically-enabled supply chain management (e-SCM) diffusion basically "involves both internal diffusion among functional units within an organisation and external diffusion across a large number of inter-organisational trading partners" (Wu and Chuang, 2009:302).

Despite these empirical results, Oliveira et al., (2010) and Ifinedo (2011) maintain that the importance of the perceived benefits of implementing technological innovations entrenches the benefit of organisation members in terms of real-time communication, decreased inventory and increased service levels. Lin and Huang (2012:162) reveal that "perceived benefits, knowledge management capability, and trading partner influence are important factors shaping eSCM systems diffusion". The e-SCM systems diffusion improves accelerated e-SCM development and provides new ways to integrate web-based technologies with core businesses that affect both cross-functional (inside) and extended crossenterprise (outside) value chain networks for business transformation (Wu and Chuang, 2009; Tarofderet al., 2010; Lin and Huang, 2012).

\subsection{Risk Pooling}

The strategy of risk pooling has been designed to "bring about demand aggregation across locations or time, in order to reduce the variability which is measured by either the standard deviation or the coefficient of variation" (Cai and Du, 2009:709). Risk pooling assumes that the demand at the markets served by the warehouses is negatively correlated ("when demand at one market is greater than average, then demand at another market will be less than average"). It means that the greater the positive correlation between demands, the smaller the benefit due to risk pooling (Hopp and Spearman, 2008, Wisner et al., 2008, Cachon and Terwiesch, 2009). According to Snyder and Shen (2011:273) "the 
information in variability is additive in the centralised system but multiplicative in the decentralised system with shared demand information as a significant factor to reduce bullwhip effect". According to Simchi-Levi et al., (2008) "the benefit of risk pooling in a centralised system depends on the standard deviation $(\sigma)$ or the coefficient of variation $(\sigma / \mu)$ among the different markets with support of eSCM system". The higher the standard deviation or coefficient of variation, the greater the potential benefit from a centralised system, although the benefit of risk pooling also depends on the demand correlation among the different markets. Arguably, a decentralised supply chain allows the manufacturer to greater proximity to consumers with quasi-actual demand information (Simchi-Levi et al., 2008).

The risk pooling strategy focuses on minimising the supply chain cost through extensive use of newsvendor model. Simch- Levi, et al., (2008), and Cachon and Terwiesch (2009) describe the newsvendor model or the newsboy model as "a single-period single-product inventory mode, which is a desirable tool for making a decision" when there is a "too much-too little" challenge. According to Cai and Du (2009:710) "bet too much and there is a cost, such as the cost for holding the leftover inventory; however, bet too little and there is a different cost, such as the opportunity cost of lost sales".

\section{Research Methodology}

\subsection{Research design}

The research design outlined a plan and structural framework of how the researcher intended to conduct the study to solve the research problems (Cooper and Schindler, 2008:140). The overall research design was exploratory survey on the empirical research design framework that constituted the blueprint for the data sources, data collection, data sampling methods and measurement, and statistical analysis of data. This design manifested the plan and structure of the investigation so conceived as to obtain answers to the research questions on bullwhip effect, and electronically-enabled supply chain management (e-SCM) systems. Blumberg, Cooper and Schindler (2008:195) cited Kerlinger (1986:279) that "a research design expresses both the structure of the research problem and the plan of investigation used to obtain empirical evidence on relation of the problem". This study used cross-sectional quantitative approach(that is, measurements were taken at one point in time on numerical exploration) to analyse data, and the self-administered questionnaire survey instrument was used for the data collection.

\subsection{Data Sources}

The organisations in retail sales, logistics, warehousing, marketing, manufacturing and information technology hubs were the units of analysis in this study, as such the managers (senior and functional levels) including supervisory level (nonmanagerial) are the subjects within the organisations. Although the supervisory positions, known as nonmanagerial category, have been considered for their reliable information and comprehensive understanding of individual retail outlets as well as retail warehousing systems, the senior executives were ideal participants for this study. Nevertheless, it is crucially important for this study to make inferences with intelligibly thoughts, sound rational and, above all, cooperative attitudes to produce integrated research on new knowledge and solution-based findings.

\subsection{Data Collection}

\subsubsection{Survey Instruments}

A survey instrument incorporating a list of cases from bullwhip effect, inventory positioning, information sharing, electronic supply chain management and strategic global optimisation activities has been constructed based on the literature reviewed. The content validity of the instrument is established by grounding it in existing literature. A self-developed survey instrument was designed based on the constructs of the conceptual framework using structured questionnaires to enhance research objectivities. While it could be argued that objective scales are more insightful, the study uses the subjective scales because of the multi-sectorial nature of the survey.

Sekaran and Bougie (2009:197) describe the questionnaire as an efficient data collection mechanism with a preformulated, written set of questions to which respondents record their answers, usually within rather closely defined alternatives. The pre-formulated thematic instrument (bullwhip effect, information sharing, inventory positioning and optimisation strategies) was grounded within the extant literature review and it was pre-tested using key industry practitioners and academics on discipline-based for suitability to enhance face and content validity. The survey 
questionnaire was structured into five sections with section one included typical demographic, personal profile and general information for both the company and individual respondents; representing nominal data (mutually exclusive and collectively exhaustive) and rank-ordered statements (ordinal data). Section two included dichotomous questions (Yes or No) on general perceptions of, inventory management systems to mitigate bullwhip effect, representing nominal data. Sections three and four included interval data with a series of statements that covered operational supply chain networks on bullwhip effect, information sharing, electronic supply chain management integration and global optimisation strategies to ameliorate bullwhip effect. According to Anderson (2009:312) the clarity about research questions and types of data collected should allow the researcher to identify the most appropriate quantitative data analysis tools to use on the main underlying option for parametric and/or non-parametric data (Collis and Hussey, 2009; Cooper and Schindler, 2008; Davies, 2007; Hair et al., 2003). The last section enlisted numerous e-SCM systems that were being used or to an extent recommended by the respondents.

Respondents indicated the degree of agreement or disagreement, where 5 represented "strongly agree" and 1 represented "strongly disagree". In other words, multi-question Likert-type five point scales ranged from strongly agree to neutral to strongly disagree on sections three and fourwere used to derive composite scores of data for each variable as representative of interval data. The respondents were assured that the researcher will not disclose the names of the participating firms or individual respondents to honour the confidentiality of the participants from an ethical point of view. The anonymity of respondents tends to yield confidence and create avidity around participation in a research study. The extensive organizational levels question on executives, functional managers and non-managerial supervisory staff seem to provide responses at the personal and business levels with proviso of assurance for anonymity and confidentiality.

\subsection{Data sampling methods and measurement}

A nonprobability sample that conformed to this study's criteria with purposive sampling is called judgment sampling. Nonprobability sampling has some compelling practical advantages to meet the sampling objectives of the study (Blumberg, Cooper and Schindler, 2008:235). This sampling occurs when a researcher selects sample members to conform to some criterion (Cooper and Schindler, 2008: 397). This method calls for special efforts to locate and gain access to the individuals that do have the requisite information. Convenience sampling was identified based on the design of deliberate sampling for heterogeneity, in which one defines target ranks and departmental persons, and ensures that a wide range of instances from within each echelon are represented. Sekaran and Bougie (2009:276) describe convenience sampling as perhaps the best way of collecting information quickly and efficient from members of the population who are available to provide it. Referral sampling proved to be the most efficient and effective approach that eventually yielded the majority of the potential respondents on the sampling frame. Snowball sampling relies on approaching few individuals from the relevant population and these individuals then act as informants and identify other members from the same population for inclusion in the sample (Welman, Kruger and Mitchell, 2005:69).

The retailers (downstream supply chain) and capacitated suppliers (mid and upstream supply chain) in the selected FMCG industry constituted the population of 800 proportionate representative within five major retail chain stores in eThekwini Metro, South Africa and approximately 300 selective suppliers for these retail groups in food (dairy, frozen, canned and general) and beverages (hot and cold), and personal health care category were considered for this empirical research study.The sample size of 456 (260 retailers and 196 suppliers) was considered where Sekaran (2003:295) alludes to the fact that sample sizes of larger than 30 and less than 500 are appropriate for most research on population-to-sample size table. According to Sekaran (2003:294) and Bartlett, Kotrlik and Higgins (2001:48) the representative population size of 800 (retailers) and 300 (suppliers) in determining minimum returned sample size is 260 and 196 sample size respectively with an alpha of 0.05 and a degree of accuracy of 0.05 . The alpha value or level of significance (0.05) would become enshrined as the threshold value for declaring statistical significance in this study. This study has produced a sample size of 448 respondents with return rate of $98 \%$ [(448/456) 100]. According to Krejcie and Morgan (1970) researchers typically set a sample size level of about 500 to optimally estimate a single population parameter, in turn, this will construct a 95\% confidence interval with a margin of error of about $\pm 4.4 \%$ for large populations. Regarding an inverse relationship between sample size and the margin of error, smaller sample sizes will yield larger margins of error. Larger sample size generally leads to increased precision when estimating unknown parameters (Cooper and Schindler, 2008; Babbie and Mouton, 2001; Krejcie and Morgan, 1970).

\subsection{Administering Survey}

The method of distributing the questionnaire was self-administered through scheduled delivery and collection of 
questionnaires within the agreed time intervals to enhance the return rate. The questionnaires were delivered to individual gatekeepers to administer the survey within their domain and most questionnaires were personally administered by the researcher within the eThekwini Metro, South Africa. The relevant letters (gatekeeper's letter, ethical clearance certificate, and consent letter to ensure confidentiality and anonymity) were constantly depicted to the gatekeepers where the researcher was given a permission to enchroach their domain.

\subsection{Statistical Analysis of Data}

The statistical analysis is aimed to examine the research objective for this study. The summarisedunivariate technique examined the distribution of cases on one variable at a time using descriptive statistics (mean and standard deviation). The multivariate analysis as statistical technique was organised around a scheme on dependence (regression analysis) procedures for underlying objective to develop models and dimensions that best describe the population as a whole.

\subsection{Frequencies}

Figure 1.1: Operational relations between trading supply chain partners on causes and mitigations of bullwhip effect (four factors)

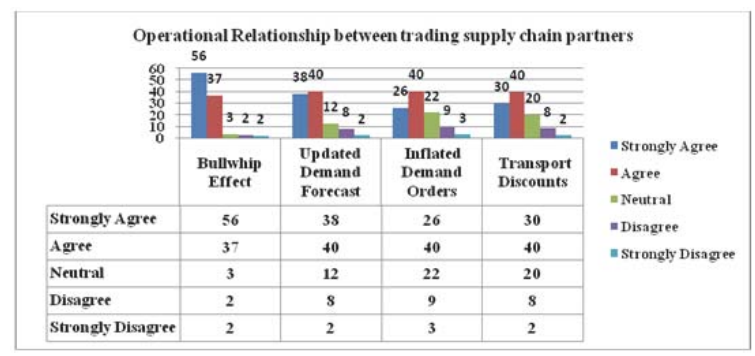

Figure 1.1 reveals the magnitudes of agreement among the respondents in relation to the operational partnerships. In terms of the phenomenon of bullwhip effect, $93 \%$ irrepressible majority of the respondents agreed that demand order variability has harmful effects in the fast moving consumer goods industry. The tendency of variability of order rates increases as orders pass through the echelons of a supply chain despite a concerted participation in updating the demand forecast (78\%) across the stream sites of supply chain. Interestingly, most respondents (70\%) agreed that organisations tend to order large quantities to take advantage of transport discount. While $66 \%$ of the respondents agreed on placing inflated orders during shortage periods to contribute towards cascading effect. The rationing and the shortage gaming tend to increase the safety stock target that further distorts the demand signal.

Figure 1.2: Operational relations between trading supply chain partners on causes and mitigations of bullwhip effect (three factors)

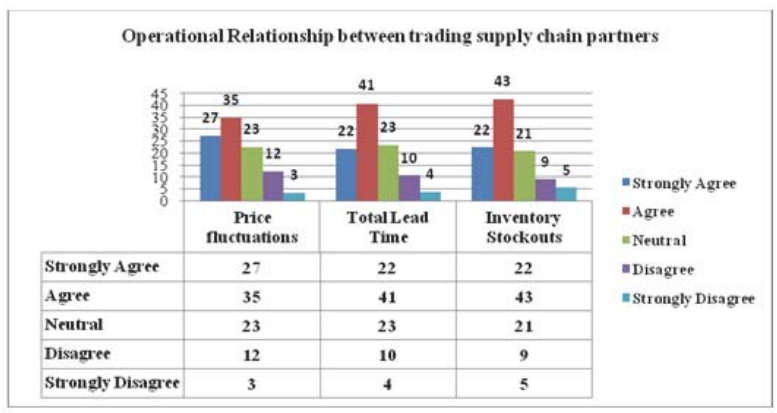

Figure 1.2 indicates that $62 \%$ of the respondents agree with the statement that price fluctuation encourages the organisations to purchase in large quantities during promotions. This disclosure is underscored by $65 \%$ of the 
respondents in the supply chain where organisations often set desired service coverage by holding a large inventory to prevent stockouts. Despite these practices, $63 \%$ of the respondents agree that supply chain trading members are constantly trying to reduce total lead time in terms of material, information and delivery lead times and delays. It is worth noting the minimal indifference of $23 \%, 23 \%$ and $21 \%$ for price fluctuation, lead time and inventory stock outs respectively.

\subsection{Descriptive Statistics}

Measures of dispersion and central tendency give a summary indication of the distribution of cases and an average value by describing single variable within the exploratory study.

Table 1.1: Descriptive Statistics on information sharing and electronic supply chain management

\begin{tabular}{|c|c|c|c|c|c|c|c|c|c|c|c|c|}
\hline Items & $\mathbf{N}$ & Mod & Min & Maxi & Mean & $\mathrm{SD} / \sigma$ & $\mathrm{S}^{2}$ & Skew & Kurt & Med & Sigma BWE & Alpha \\
\hline $\begin{array}{l}\text { Electronic S C M Systems. } \\
\text { Updated Demand Forecast } \\
\text { Information Sharing } \\
\text { Transport Discounts } \\
\text { Integrated E-SCM systems } \\
\text { Information Velocity. } \\
\text { Valid Total }\end{array}$ & $\begin{array}{l}448 \\
448 \\
448 \\
448 \\
448 \\
448 \\
448\end{array}$ & \begin{tabular}{|l|}
4.00 \\
4.00 \\
4.00 \\
4.00 \\
4.00 \\
4.00
\end{tabular} & $\begin{array}{l}1.00 \\
1.00 \\
1.00 \\
1.00 \\
1.00 \\
1.00\end{array}$ & $\begin{array}{l}5.00 \\
5.00 \\
5.00 \\
5.00 \\
5.00 \\
5.00\end{array}$ & $\begin{array}{c}4.4554 \\
4.0402 \\
3.9955 \\
3.8460 \\
3.8013 \\
3.6987 \\
79.2478\end{array}$ & $\begin{array}{c}.85020 \\
.99583 \\
.96237 \\
1.03666 \\
.98911 \\
1.06429\end{array}$ & \begin{tabular}{|c|}
.723 \\
.992 \\
.926 \\
1.075 \\
.978 \\
1.133
\end{tabular} & $\begin{array}{l}-2.164 \\
-1.050 \\
-.929 \\
-.802 \\
-.471 \\
-.539\end{array}$ & $\begin{array}{l}2.487 \\
.627 \\
.531 \\
.155 \\
-.610 \\
-.491\end{array}$ & $\begin{array}{l}4.57 \\
4.20 \\
4.13 \\
3.98 \\
3.88 \\
3.80\end{array}$ & $\begin{array}{l}.000 \\
.000 \\
.000 \\
.000 \\
.001 \\
.127\end{array}$ & $\begin{array}{l}.842 \\
.833 \\
.835 \\
.834 \\
.834 \\
.832 \\
.840\end{array}$ \\
\hline $\begin{array}{l}\text { Std error of Skew }=0.115 \\
\text { Std error of Kur }=0.230\end{array}$ & & & & & & & & & & & & \\
\hline
\end{tabular}

This section of the study advocates that e-SCM systems $(M=4.56)$ are the most significant systems. These systems seem to create agility and high flexibility that rapidly respond to changing market requirements from diverse customers by quickly delivering the right products and services through effective integration. The respondents ranked the e-SCM system with a standard deviation of 0.850 as "a mechanism to integrate trading supply chain partners at technical, operational and business level with efficient real-time information sharing and active coordination" to mitigate bullwhip effect (Keet al., 2009:839).

The semantic view of electronically-enabled supply chain management underpins the effective updated demand forecast ( $\mathrm{M}=4.04$ with 0.996 std deviation) wherein the organisations jointly participate in updating the demand forecast across the stream sites of supply chain. Although the electronically-enabled supply chain management systems are preferably significant to improve flexibility, future strategic communication $(M=3.88)$ and informal and formal information sharing ( $M=3.92)$ in the dynamic market, as well as information exchange $(M=4.00)$, are associated with high order fulfillment rate and the shorter order cycle time to enhance supply chain performance targets in the FMCG industry. The respondents agree that information volatility $(M=3.56)$ creates unstable demand and supply uncertainty with information content, format and timing. Only the quality of information $(\mathrm{M}=3.73$ with 1.047 standard deviation) and the magnitude of information velocity ( $M=3.70$ with 1.064 standard deviation) enable organisations to produce dependable delivery and contribute positively to customer satisfaction and service level of supply chain performance.

The integrated e-SCM systems $(M=3.80)$ provide flexibility to respond $(M=3.61)$ to emergency demand order changes despite the frequent practice that the organisations constantly hold a large inventory to avert inventory stock outs $(\mathrm{M}=3.68)$. The respondents agree that electronically-enabled supply chain system has significant role (highly ranked $M=4.46)$ to improve willingness to share sensitive and confidential information $(M=3.60)$ based on trust, to offer greater control and access to advanced economic information $(M=3.66)$. Additionally, the system will enhance profitability level $(M=3.70)$ and establish common goals and mutual dependency $(M=3.63)$ between collaborating supply chain partners to further optimise inventory positioning $(M=3.65)$ with significant reduction in lead times $(M=$ 3.75). Organisations tend to order large quantities to take advantage of transport discount $(M=3.85)$ despite a concerted effort to reduce total lead time $(M=3.67)$ in terms of material, information and delivery lead times and delays. The respondents agree that price fluctuations $(M=3.70)$ tend to inflate demand orders $(M=3.77)$ during promotions and shortage periods. 


\subsection{Multiple Regression analysis Bullwhip effect and all predictor variables}

Multiple regression analysis was conducted in order to assess how much variance in the dependent variable is explained by the independent variable. This omnibus method incorporated thirty one interval-level variables to analyse the relationship between the criterion variable of bullwhip effect and three major possible predictor variables (e-SCM system, inventory positioning, and information sharing together with their subdimensions), and each explanatory variable from global optimisation strategies. The purpose of this method is to reveal and understand the possible predictor variables with potential contribution to the dependent variable (bullwhip effect) in the model of the study. The results of multiple regression has relative importance of individual predictors from $\beta$ coefficients that depict the omnibus explanatory power of all predictor variables with measures of $\mathrm{R}^{2}$.

According to Nusair and Hau (2010:315) "the values of $\mathrm{R}^{2}$ or adjusted $\mathrm{R}^{2}$ indicate the amount of variance in the outcome explained by all predictors taken together". The tests (t-test, F-ratio and Durbin-Watson test) will allow the determination of the statistical significance of the results, both in terms of the model itself and the individual independent variables. In the same model, the major assumptions for multiple regression are described to evaluate potential problems or disclose the probable violation of assumption in the model with regard to outliers, normality, linearity, homoscedasticity and independence of residuals (Mahalanobis distances, Cook's distances and leverage $h$ hat).

Table 1.2: Model Summary and ANOVA

Model Summaryh

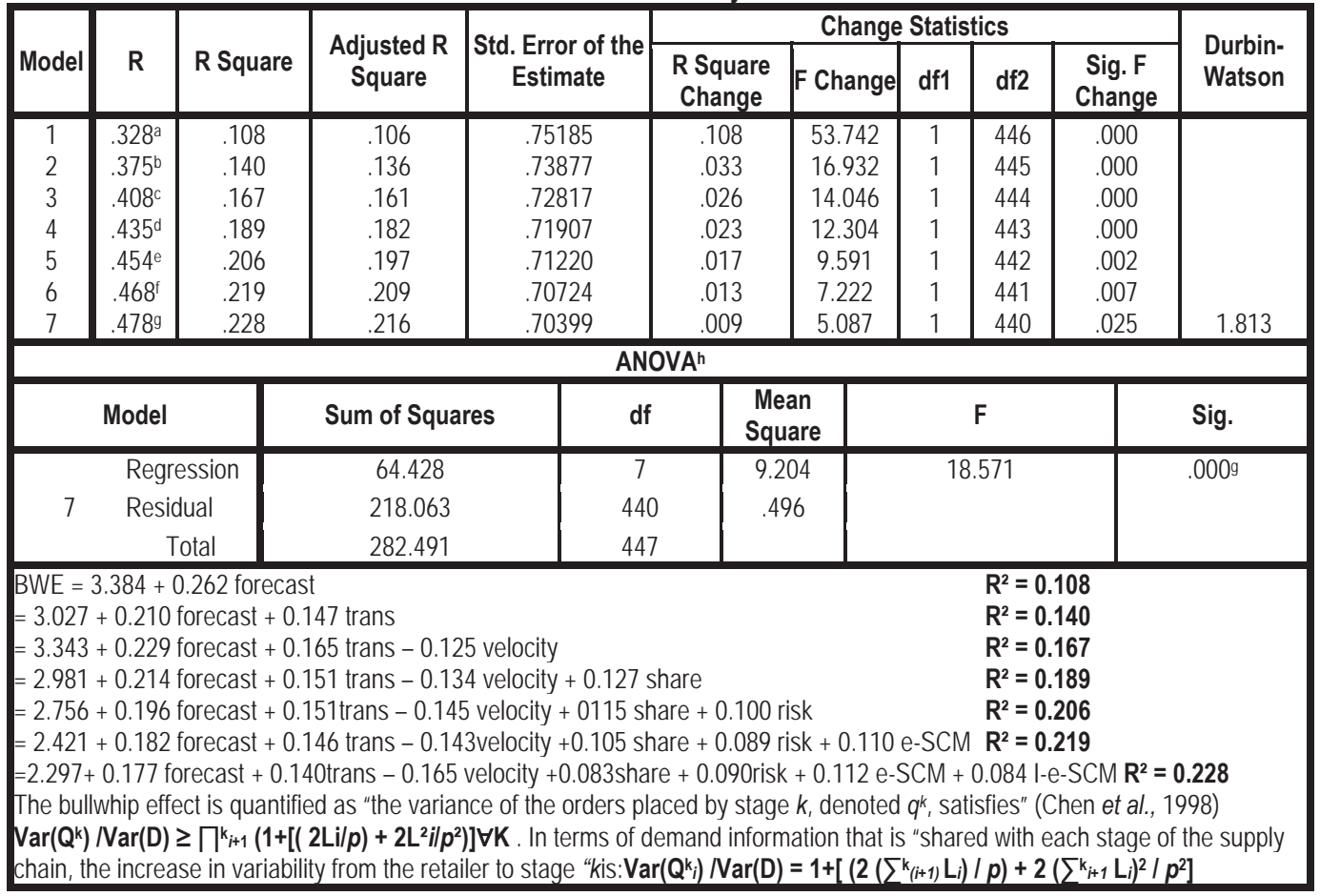

In general, predictive models (seven models) of bullwhip effect are derived by multiple regression analysis unstandardised coefficients using the stepwise procedure for thirty possible explanatory variables as follows: $(Y=$ Bullwhip effect -BWE from Model 1 to 7).It is noted by Snyder and Shen (2011) and (Simchi-Levi et al., 2008) that for supply chains with centralised information, the increase in variability at each stage is an additive function of the lead time and the lead time squared, while for supply chains without centralised information, the lower bound on the increase in variability at each stage is multiplicative. This implies that 'centralising customer demand information' can significantly ameliorate the bullwhip effect. Bullwhip effect measure over the entire supply chain allows one to compare different system configurations from the stability point of view. In identifying the bullwhip occurrence at each stage of the supply 
chain it is proposed to compare a standard deviation of demand faced by the neighbour supply chain stages by calculate a ratio $B E_{i:}$ :

$$
B E_{i}=\frac{\operatorname{STD}\left(Q_{i}\right)}{\operatorname{sTD}\left(Q_{i-1}\right)} \in(0, \infty), i=\overline{1, n:}
$$

If $B E_{i}>1$ then the bullwhip effect exists and if $B E_{i} \leq 1$ then the bullwhip effect does not exist at $n$ (number of supply chain stages). STD $\left(Q_{i}\right)$ means standard deviation of orders placed by stage $i$ to its supplier; and $\operatorname{STD}\left(Q_{i-1)}\right.$ means standard deviation of demand received by supply chain stage $i$. According to Simchi-Levi et al., (2008) the performance of the supply chain is evaluated under various factors such as end customer mean demand $E(X)$ and its standard deviation $\operatorname{STD}(X)$, lead time LT, safety stock factor $z$ and number of observation on which further demand forecast is based $p$ implementing both decentralised and centralised information sharing strategies, although for the supply chain with centralised information sharing, the variation of placed orders travelling upstream is visibly smaller.

The validity of the final model is assessed by considering the correlation of coefficients and determination, and thoroughly examining the consistency between the model and response results through $t$-test, $F$-test and Durbin-Watson test without assuming the superiority of the model from a high value for the coefficient regression.

Table 1.3: Coefficients and Residuals statistics

\begin{tabular}{|c|c|c|c|c|c|c|c|c|c|c|c|c|}
\hline \multicolumn{13}{|c|}{ Coefficients $^{a}$} \\
\hline \multirow{2}{*}{ Model } & \multicolumn{2}{|c|}{$\begin{array}{l}\text { Unstandardised } \\
\text { Coefficients }\end{array}$} & \multirow{2}{*}{\begin{tabular}{|c|}
$\begin{array}{c}\text { Standardised } \\
\text { Coefficients }\end{array}$ \\
Beta \\
\end{tabular}} & \multirow{2}{*}{$t$} & \multirow{2}{*}{ Sig. } & \multicolumn{2}{|c|}{$\begin{array}{c}95.0 \% \text { Confidence } \\
\text { Interval for B }\end{array}$} & \multicolumn{3}{|c|}{ Correlations } & \multicolumn{2}{|c|}{$\begin{array}{l}\text { Collinearity } \\
\text { Statistics }\end{array}$} \\
\hline & B & Std. Error & & & & \begin{tabular}{|l|} 
Lower \\
Bound
\end{tabular} & $\begin{array}{l}\text { Upper } \\
\text { Bound }\end{array}$ & $\begin{array}{l}\text { Zero- } \\
\text { order }\end{array}$ & Partial & ||Part & $t \mid$ Tolerance & VIF \\
\hline (Constant) & 2.297 & .258 & & 8.901 & .000 & 1.790 & 2.805 & & & & & \\
\hline $\begin{array}{l}\text { Updated } \\
\text { Forecast }\end{array}$ & .177 & .037 & .222 & 4.780 & .000 & .104 & .250 & .328 & .222 & .200 & .816 & 1.226 \\
\hline $\begin{array}{l}\text { Transport } \\
\text { Discounts }\end{array}$ & .140 & .035 & .183 & 4.040 & .000 & .072 & .209 & 281 & 189 & .169 & .854 & 1.171 \\
\hline $\begin{array}{l}\text { Information } \\
\text { Velocity }\end{array}$ & -.165 & .034 & -.220 & -4.869 & .000 & -.231 & -.098 & -.072 & -.226 & .204 & .856 & 1.168 \\
\hline $\begin{array}{l}\text { Information } \\
\text { Sharing }\end{array}$ & .083 & .037 & .100 & 2.213 & .027 & .009 & .156 & .213 & .105 & .093 & .861 & 1.161 \\
\hline Risk Pooling . & .090 & .032 & .122 & 2.771 & .006 & .026 & .153 & .197 & .131 & .116 & .912 & 1.096 \\
\hline $\begin{array}{l}\text { E-SCM } \\
\text { Systems. }\end{array}$ & 112 & .041 & .120 & 2.746 & .006 & .032 & .192 & .225 & .130 & .115 & .920 & 1.087 \\
\hline $\begin{array}{l}\text { Integrated e- } \\
\text { SCM systems }\end{array}$ & .084 & .037 & .105 & 2.255 & .025 & .011 & .158 & .152 & .107 & .094 & .813 & 1.230 \\
\hline \multicolumn{13}{|c|}{ Residuals Statistics ${ }^{a}$} \\
\hline & & & \multicolumn{2}{|c|}{ Minimum } & \multicolumn{2}{|c|}{ Maximum } & \multicolumn{2}{|l|}{ Mean } & \multicolumn{2}{|c|}{\begin{tabular}{|c|} 
Std. \\
Deviation
\end{tabular}} & \multicolumn{2}{|l|}{ N } \\
\hline \multicolumn{3}{|c|}{$\begin{array}{l}\text { Mahal. Distance } \\
\text { Cook's Distance } \\
\text { Centered Leverage Value }\end{array}$} & \multicolumn{2}{|l|}{$\begin{array}{l}.451 \\
.000 \\
.001\end{array}$} & \multicolumn{2}{|c|}{$\begin{array}{l}33.125 \\
.098 \\
.074\end{array}$} & \multicolumn{2}{|l|}{$\begin{array}{l}6.984 \\
.003 \\
.016\end{array}$} & \multicolumn{2}{|c|}{$\begin{array}{l}5.185 \\
.010 \\
.012\end{array}$} & \multicolumn{2}{|l|}{$\begin{array}{l}448 \\
448 \\
448 \\
\end{array}$} \\
\hline
\end{tabular}

a. Dependent Variable: Bullwhip Effect

This analysis has incorporated the interval-level variable to analyse the relationship between the criterion variable of bullwhip effect and three major possible predictor variables (e-SCM system, inventory positioning and information sharing together with their subdimensions), as well as each explanatory variable from global optimisation strategies. These sections constituted the explanatory variables to explain the predictive power of relationship with the amplification of consumer demand order variability travelling upstream the supply chain network. The predictive model (model 7) of bullwhip effect was developed using the stepwise procedure from thirty possible explanatory variables. The validity of this model was assessed considering the correlation of coefficient and determination (adjusted $\mathrm{R}$ square $=0.0216 ; F_{7,440}=$ $18.571 ; p$-value $=0.000$ less than 0.05 ) as the proportion of variance accounted for by the model. The $F$-ratio cited the significant of the model while the strength of the model accounted $22 \%$ (adjusted $\mathrm{R}^{2}$ percentage) of the variance in the criterion variables. Durbin-Watson test disclosed a consistent value of 1.813 (ranging between the threshold of 1.5 and 
2.5) indicating no problems related to multicollinearity while the $t$-values were appropriate with $t$-significance values less than 0.05 to validate the model and individual independent variables. In terms of multiple regression assumptions, none of the assumptions were violated in the model with regard to outliers, normality (both normal plot of the residuals produced satisfactory points close to a diagonal line, and partial regression plot produced acceptable random scatter of points with constant variability) and linearity (no multicollinearity problems with VIF greater than 10 ranging between 1.096 and 1.230).

The respective statistics residuals (Mahalanobis distance, Cook's distance and leverage $h$ hat) performed within their thresholds indicating no outliers.Cook's distance $\left(\mathrm{D}_{\mathrm{i}}\right)$ captures the impact of an observation from two sources: the size of changes in the predicted values when the case is omitted (outlying studentised residuals), as well as the observation's distance from the other observations (leverage) (Hair, 1998:225). A rule of thumb is to identify observations with a Cook's distance of 1.0 or greater (Tabachnick and Fidell, 2007), and this study has maximum value (0.098) as measure of overall fit and suggests no problem. The hat value has the range of possible values between 0 and 1 , and the average value is $p / n$, where $p$ is the number of predictors (the number of coefficients plus one for the constant) and $n$ is the sample size. If the $p$ is greater than 10 (thirty for this study) and the sample size exceeds 50 (448 for this study), the rule of thumb is to select observations with a leverage value greater than twice the average $(2 p / n)$. This study has the threshold limits of $2 p / n$ because the sample size exceeds $50(n=448)$ with maximum centred leverage value of 0.074 . The degree of leverage is an important element in studying the effect of extreme values, wherein the diagonals of the hat matrix $\left(h_{i}\right)$ are measures of leverage in the space of the independent variables. Mohalanobis distance $\left(D^{2}\right)$ is the measure of the uniqueness of a single observation based on differences between the observation's values and the mean values for all other cases across all independent variables (this study reveals - minimum $=0.451$ and maximum $=33.125$, with mean $=6.984$ and std deviation $=5.185$ ). . The empirical evidence of this study produced seven explanatory variables (updated forecast demand, transport discounts, information velocity, information sharing, risk pooling, e-SCM systems and integrated e-SCM system) from the full model with $\mathrm{R}^{2}(0.023)$, adjusted $\mathrm{R}^{2}(0.22)$, -ratio $(18.571), d f(1 ; 140)$ and $p=$ 0.000 .

\section{Discussion and Conclusion}

Accurate forecasting: This implies that linking the inventory positioning and order replenishment frequencies among supply chain members with accurate forecasting models reduce the pernicious effect of amplified consumer demand order variability. According to Trapero and Fildes (2012:739) forecasting accuracy is directly connected to inventory positioning and management, and lower errors result in reduced stock keeping and inventory investment without compromising the service level. This study infers that accurate forecasting models with integrated sales information from the retailer and information transparency in the supply chain enhance the degree of positioning inventory and frequencies of order replenishment rate to obviating order information distortion in the upstream site.

Transport discounts: In the elementary cause of bullwhip effect, organisations tend to order large quantities to take advantage of transport discounts. Inventory quantity decisions are impetus management of frequency and size of shipments from plants to the distribution centers (DCs) and to the retailers based on different replenishment policies. Poor integration between supply chain partners dampens the efforts of harmonising inventory cost and time-based delivery performance. The swift solution compels the supply chain members to take advantage of full load transport discount and consequently impacts the operational performance outcomes with large quantities of inventory. If the supply chain partners leverage their performance by reducing demand variability upstream, they can achieve optimal investment decision on inventory quantities rather than amplifying supply variability with transportation discounts.

Information velocity: It is puzzling to discover that information velocity does not improve information flow and does not tame order variability. If information sharing is dependent on integrated e-SCM systems, supply chain coordination data sharing and the effect of willingness would be constrained by clockspeed element to access information and degree of responsiveness to distorted information. This study tentatively suggests that the information volatility evokes a mismatch with a degree of information velocity and eventually languishes to subdue consumer demand order information distortion, also known as bullwhip effect.

Information sharing: Information sharing achieves supply chain coordination and mitigates consumer demand order variability. The level of supply chain coordination is associated with degree of uncertainty in the partnership relationship and collaborative processes from the underlying primary principle to proactively sharing supply chain demand order information. The sharing of supply chain information is normally template-based on a specified contract and described data format (Croson and Donohue, 2006) to entrench a sufficient level of coordination to share data (on consumer demand order forecasts and replenishment, sales and order status, and limited company bound information). Despite the 
dearth of willingness element on constrained information, the successful supply chain collaborative sharing and information under these compelling circumstances gradually builds coordination partnership, trust and commitment, and better communication. In mitigating bullwhip effect, Du et al., (2012:89) provide empirical evidence that when partnerships become entrenched and coordinated, the willingness to share template-based information increases and consequently the willingness to proactively share advance economic information. This study provides empirical evidence that information sharing allows supply chain coordination-data exchange (CDE) to ameliorate the consumer demand order variability (DoV) form visible inventory level and order status.

Risk pooling: The empirical findings in this study predicted that risk pooling reduces the consumer demand order variability by aggregating demand across locations. The retail supply chain has an obligatory mandate to retail for continuously improving levels of customer service while concurrently reducing costs of inventory, distribution and transportation to maintain profit margins. As goods flow through several stages from tiers of suppliers to customers, a coordinated supply chain network should consolidate distribution locations to entrench risk pooling. Lee and Knon (2010:94) interpret a supply chain network as "the logistic network which consists of facilities, customers, products in the procedure of the planning, coordination, controlling inventory and distribution". In decelerating the pernicious effect of consumer demand variability, supply chain consolidated inventory from several locations (inventory pooling) takes advantage of the risk pooling on consumer demand orders to control variability. Eventually, this could reduce inventory costs, improve supply chain performance and enhance product availability. Underpinning the demand switching processes as inventory pooling, Hsieh (2011:137) captures the benefits of the risk pooling effect if one aggregate demand orders across product locations to reduce consumer demand order variability in the supply chain network.

E-SCM systems: This study predicted that e-SCM systems mitigate bullwhip effect in the supply chain network. Electronic systems in supply chains depicted an associative role to swiftly reflect amplified changing consumer demand orders in the supply chain network. The research results tentatively suggest that the supply chain partners can electronically integrate information flow, products and services effectively. Subsequently build business relationships that quickly and accurately respond to consumer demand variability. This study focused on both internal e-SCM diffusion among functional units within the organisation and external diffusion across inter-organisational supply chain trading partners. The literature review (chapter five) identified a number of positive and negative empirical permutations on eSCM diffusion, however this study explores the role of e-SCM systems in retail supply chain to manage bullwhip effect. The central principle of an e-SCM diffusion is the creation of electronic flexible supply chain partnership network to facilitate a mutual decision making process across the retail supply chains partners. There are a number of challenges including partnership trust, technology compatibility, security of information flow and complexity of implementation, nonetheless this study empirically found e-SCM systems to be a key success factor in supply chain management processes to manage the phenomenon of bullwhip effect.

Integrated e-SCM systems: This explanatory variable predicted that integrated e-SCM systems improve information sharing. Sambamurthyet al., (2005:237-263) support that supply chain aligned and integrated IT systems on business processes and IT activities enable supply chain agility across the supply chain network. These integrated IT processes built on underlying four strategic domains including business strategy, IT strategy, organisational infrastructure and processes, and IT infrastructure and processes (Du et al., 2012). The magnitude of supply chain electronic integration and close linkage without legal constraints to hinder information velocity should be the reflection of successful information sharing and proper management of bullwhip effect. This particular study suggests improved information sharing from the underlying aligned and integrated e-SCM systems to alleviate the magnitude of bullwhip effect. Traperoet al., (2012:739) further propose that the electronically-enabled supply chain management techniques that permit the retailer's sales information be integrated into the supplier's planning process to alleviate supply chain demand variability amplification.

\section{Conclusion}

The value of centralised information flow mapping (CIFM) on demand order informant prevails from internal and external information-based linkages. These interconnectivity activities improve velocity of information flow with better content and format as added value to the supply chain performance. The value-based information sharing depends on integrated eSCM systems and quality of information shared to improve supply chain responsiveness and frequencies of order replenishment capabilities. This study further recommend that the quality of electronically-integrated supply chain information sharing yields the maximum likelihood of odds to an improvement of supply chain business performance as less likely that the retail supply chain could experience the presence of oscillating bullwhip effect. The retail supply chain migration to CscD system as the consolidated distribution strategy for either lead time pooling, risk pooling, inventory 
locations pooling or supply pooling brings retail inventory closer to customers with optimum position of inventory. If both stream sites adopt central supply chain system, the likelihood of odds to improve operational supply chain performance would depend on real-time quality information and how inventory is optimally positioned and the inventory policies are effectively controlled to mitigate bullwhip effect. The retail supply chain would need a CScD system that focuses on directly involving capacitated suppliers in their initiatives to realise high levels of customer service satisfaction. A central supply chain system indicated superiority over decentralised system in the empirical research.

\section{References}

Anderson, V. (2009).Research Methods in Human Resource Management. 2nd Ed., London: Chartered Institute of Personnel Development.

Babbie, E. and Mouton, J. (2001). The practice of social research. Cape Town: Oxford.

Balan, S., Vrat, P. and Kumar, P. (2009). Information distortion in a supply chain and its mitigation using soft computing approach'. Omega 37: 282-299.

Bartlett, J.E., II, Kotrlik, J.W., and Higgins, C. (2001). 'Organisational research: Determining appropriate sample size for survey research'. Information Technology, Learning and Performance Journal, 19(1) 43-50

Blumberg, B, Cooper, D. R. and Schindler, P. S. (2008).Business Research Methods. New York: McGraw-Hill International.

Brown, S. (2008). Measures of Shape: Skewness and Kurtosis. New York: Oakes Road Systems, Tompkins Cortland Community College.

Cachon, G. and Terwiesch, C. (2009).Matching supply with Demand: An introduction to Operations Management. Boston: McGraw-Hill Irwin.

Cachon, G. and Terwiesch, C. (2009).Matching supply with Demand: An introduction to Operations Management. Boston: McGraw-Hill Irwin.

Cai, X. and Du, D. (2009). 'On the Effects of Risks Pooling in Supply Chain Management: Review and Extensions'. ActaMethematicApplicatae, 25(4) 709-722

Chae, B., Yen, H.R. and Sheu, C. (2005). 'Information technology and supply chain collaboration: Moderating effects of existing relationships between partners'. IEEE Transactions on Engineering Management, 52(4) 440-448

Chen, F. (2003).'Information sharing and supply chain coordination'. Operations Research and Management Science, 11:341-422

Chen, F. and Yu, B. (2005).'Quantifying the Value of Leadtime Information in a single-location inventory system'. Manufacturing Service Operations Management,7(2) 144-151.

Chiang, W.K. and Feng, Y. (2007).'The value of information sharing in the presence of supply uncertainty and demand volatility'.International Journal of Production Research, 45(6) 1429

Chopra, S. and Meindl, P. (2007).Supply chain management: Strategy, planning and operations. $3^{\text {rd }}$ Ed. New Jersey: Pearson International edition.

Cohen, J., Cohen, P., West, S.G. and Aiken, L.S. (2003).Applied multiple regression/correlation analysis for the behavioural sciences.3rd Ed. New York: Lawrence Erlboum Associates.

Collis, J. and Hussey, R. (2009).Business Research: A practical guide for undergraduate students. Basingstoke: Palgrave.

Cooper, B. R. and Schindler, P. S. (2008). Business Research Methods.10th Ed. New York: McGraw-Hill International.

Coyle, J.J., Langley Jr, C.J., Novack, R.A. and Gibson, B.J. (2013).Managing Supply Chain: A logistics Approach. 9th Ed., New York: South-Western, Cengage Learning.

Croson, R. and Donohue, K. (2006). 'Behavoural causes of the bullwhip effect and the observed value of inventory information'. Management Science, 52(3) 323-337

Croson, R., Donohue, K., Katok, E. and Sterman, J. (2005). 'Order Instability in Supply Chains: Coordination Risk and the Role of Coordination Stock'. PSU Working Paper

Davies, M.B. (2007). Doing a successful Research Project using Qualitative Methods. Basingstoke: Palgrave MacMillan.

Davis, M.D. and Heineke, J. (2005). Operations Management: Intergrating manufacturing and services. $5^{\text {th }}$ ed. Boston: McGraw-Hill.

Du, T.C., Lai, V.S., Cheung, W. and Cui, X. (2012). 'Willingness to share information in a supply chain: A partnership data-process perspective'. Information and Management, 49:89-98.

Folinas, D. Manthou, V., Sigala, M. and Vlachopoulou, M. (2004).'Modeling the e-volution of a supply chain: Cases and best practices'. Internet Research:Electronic Networking Applications and Policy, 14 (4), 274-283

Forrester, J.W (1958). 'Industrial dynamics - A major breakthrough for decision markers'. Harvard Business Review,36(4) 37-66.

Forrester, J.W (1961). Industrial dynamics. New York: MIT Press \& John Wiley \& Sons, Inc.

Gambardella, A. and McGahan, A.M. (2010). 'Business-Model Innovation: General Purpose Technologies and their Implications for Industry Architecture'. Long Range Planning,43(2/3)267-271.

Garson, G.D. (2012). Factor Analysis. North Carolina: Statistical Associates Publishing.

Hair, Jr, J. F., Babin, B, Money, A. H., and Samouel, P. (2003).Essentials of Business Research Methods. New York: John Wiley \& Sons, Inc.

Hambrick, D.C. and Fredrickson, J. (2005). 'Are you Sure You Have a Strategy?' Academy of Management Executive, 19(4)51-62.

Heizer, J. and Render, B. (2008). Principles of Operations Management. $7^{\text {th }}$ Ed., New Jersey: Pearson Education 
Heizer, J. and Render, B. (2011).Principles of Operations Management. $8^{\text {th }}$ Ed., New Jersey: Pearson Education Hopp, W. J., and Spearman, M.L. (2008).Factory Physics. $3^{\text {rd }}$ Ed. Boston: McGraw-Hill International Edition.

Hsieh, Y. (2011) 'Demand switching criteria for multiple products: An inventory cost analysis'. Omega, 39 130-137

Ifinedo, P. (2011). 'Internet/e-business technologies acceptance in Canada's SMEs: An exploratory investigation'. Internet Research, 21(3) 255-281.

Jacobs, F.R., and Chase, R.B. (2008).Operations and Supply management: The Core. $2^{\text {nd }}$ Ed., Boston: McGraw-Hill.

Kerlinger, F.N. (1986). Foundations of Behavioural Research. 3rd Ed., New York: Holt, Rinehart and Winston.

Krejcie, R.V and Morgan, D.W. (1970) 'Determining sample size for research activities.'Educational and Psychological Measurement, 30: 607-610.

Lee, H. and Whang, W. (2000). 'Information sharing in a Supply Chain'.International Journal of Technology Management, 20(3/4) 373-87 and 626-648

Lee, L. H., Padmanabhan, V. and Whang, S. (2004)). 'Comments on information distortion in a supply chain: the bullwhip effect'. Management Science,15:1887-1893

Lee, Y.H. and Kwon, S.G. (2010). 'The hybrid planning algorithm for the distribution center operation using tabu search and decomposed optimisation'. Expert Systems with Applications, 37:3094-3103

$\mathrm{Li}$, Z. and Gao, L. (2008). 'The effects of sharing upstream information on product rollover'.Production and Operations Management Society,17(5) 522-531.

Lin, F.R. and Lin, Y.Y. (2006). 'Integrating multi-agent negotiation to resolve constraints in fulfilling supply chain orders'. Electronic Commerce Research and Applications, 5(4) 313-322.

Lin, F.R. and Lin, Y.Y. (2006). 'Integrating multi-agent negotiation to resolve constraints in fulfilling supply chain orders'. Electronic Commerce Research and Applications, 5(4) 313-322.

Lin, H. and Huang, N. (2012).'Understanding the determinants of electronic supply chain management diffusion'.Business and Information, E 162-178

Lin, H. and Huang, N. (2012).'Understanding the determinants of electronic supply chain management diffusion'.Business and Information, E 162-178

Makui, A. and Madadi, A. (2007). 'The bullwhip effect and Lyapunov exponent'. Applied Mathematics and Computation, 189: 53-70

Miao, L. and Chen, J. (2005). 'Information sharing with scarce goods in cournot retailers', International Conference on Services Systems and Services Management, Proceedings of ICSSSM '05, Chonqing.

Miragliotta, G. (2006). 'Layers and mechanisms: A new taxonomy for the Bullwhip Effect'. International Journal of Production Economics, 104: 365-381

Norusis, M.J. (2012). IBM SPSS Statistics 19 statistical procedures companion. Upper Saddle River, New York: Prentice Hall.

Nunnally, J.C. (1978). Psychometric Theory. New York: McGraw-Hill

Nusair, K. and Hua, N. (2010). 'Comparative assessment of structural equation modeling and multiple regression research methodologies: E-commerce context'. Tourism Management,31: 314-324

Oliveira, T. and Martins, M.F. (2010).'Understanding e-business adoption across industries in European countries'.Industrial Management and Data Systems,110(9) 1337-1354.

Ouyang, Y. (2007). 'The effect of information sharing on supply chain stability and the bullwhip effect'.European Journal of Operational Research, 182: 1107-1121

Patnayakuni, N. and Rai, A. (2002). 'Towards a theoretical framework of digital supply chain integration', European Conference on Information systems (ECIS), Gdansk, Available: http://is2lse.ac.uk/asp/aspecis/20020127.pdf., [Accessed: 05/10/2011]

Production Economics, 104: 365-381

Sambamurthy, V., Bharadwaj, A. and Grover, V. (2003). 'Shaping agility through digital options: Reconceptualising the role of information technology in contemporary firms'. MIS Quarterly, 27(2) 237-263

Schroeder, R.G. (2008). Operations Management: Contemporary Concepts and Cases. $4^{\text {th }}$ Ed. Boston: McGraw-Hill International Edition.

Sebastian, J.G.D. and Lambert, D.M. (2003).'Internet-enabled coordination in the supply chain'.Industrial Marketing Management, 32(2) 251-263

Sekaran, U. (2003). Research Methods for business: A Skill Building Approach.4th Ed. New York: John Wiley \& Sons Inc.

Sekaran, U. and Bougie, R. (2009).Research Methods for Business: A Skill Building Approach, 5th Ed. New York: Wiley \& Sons.

Simchi-Levi, D., Kaminsky, P. and Simchi-Levi, E. (2008).Designing and Managing in supply chain: Concepts, Strategies \& Case Studies. $3^{\text {rd }}$ Ed. New York: McGraw-Hill//rwin.

Snyder, L.V. and Shen, Z.M. (2011). Fundamentals of Supply Chain Theory. New Jersey: John Wiley \& Sons, Inc.

Sorescu, A., Frambach, R.T., Singh, J., Rangaswamy, A. and Bridges, C. (2011).'Innovations in Retail Business Models'.Journal of Retailing,87S (1) S3-S16

Tabachnick, B.G. and Fidell, L.S. (2007).Using Multivariate Statistics. $5^{\text {th }}$ Ed. Boston: Pearson International Edition.

Tabachnick, B.G. and Fidell, L.S. (2007). Using Multivariate Statistics. 5th Ed. Boston: Pearson International Edition.

Tarofder, A.K., Marthandan, G. and Haque, A. (2010). 'Critical factors for diffusion of web technologies for supply chain management functions: Malaysian perspective'. European Journal of Social Sciences, 12(3) 490-505.

Teece.D.J. (2010) 'Business Models, Business Strategy and Innovation'. Long Range Planning, 43(2/3)172-194.

Towill, D.R. (1997). 'Forridge - principles of good material flow'. Production Planning and Control, 8(7)622-32. 
Trapero, J.R., Kourentzes, N. and Fildes, R. (2012) 'Impact of information exchange on supplier forecasting performance', Omega, 40: 738-747

Warburton, R.D.H. (2004). 'Analytical investigation of the Bullwhip effect'.International Journal of Production Management, New York: The Free Press.

Warburton, R.D.H., Hodgson, J.P.E, and Kim, Y.K. (2004).'An Analytical Investigation of the Bullwhip Effect NTC S03-MD13s'.NTC Project: S03-MD13s. National Textile Center Annual Report: November 2004.

Welman, J.C., Kruger, S. J. and Mitchell, B.C. (2005).Research Methodology. 3rd Ed., Cape Town: Oxford University Press Southern Africa.

Wisner, J.D., Stanley, L.L., (2008). Process Management: Creating Value along the Supply Chain, Text and Cases. Australia: Thomson South-Western.

Wisner, J.D., Stanley, L.L., (2008). Process Management: Creating Value along the Supply Chain, Text and Cases. Australia: Thomson South-Western.

Wu, D.Y. and Katok, E. (2006).'Learning, communication, and the bullwhip effect'.Journal of Operations Management, 24: 839-850

Wu, I-L.and Chuang, C-H. (2009). 'Analysing contextual antecedents for the stage-based diffusion of electronic supply chain management'. Electronic Commerce Research and Applications, 8(6)302-314

Zott, C. and Amit, R. (2010). 'Business Model Design: An Activity System Perspective'. Long Range Planning,43(2/3)216-2. 